\title{
Space and time variability analyses of the Indian monsoon rainfall as inferred from satellite-derived OLR data
}

\author{
M. A. Haque *, M. Lal \\ Centre for Atmospheric Sciences, Indian Institute of Technology, New Delhi, India
}

\begin{abstract}
Five day mean Outgoing Longwave Radiation (OLR) data from June 1974 to May 1988 (14 yr period) derived from the NOAA polar satellite are analysed to determine objectively the onset and withdrawal dates of the southwest monsoon over 7 selected regions of the Indian sub-continent and the adjoining seas. Monthly mean OLR anomalies are derived to examine the intra- as well as interannual variability of OLR distribution for each of the 7 regions. Linear correlation matrices are also constructed from standardized OLR anomalies to explain the spatial variability of OLR in individual years and to identify the statistical coherency between the regions in the years with excess, normal and deficient monsoon rainfall. Derived dates of the monsoon onset and withdrawal using OLR indices are in fair agreement with the dates of onset and withdrawal obtained based on the rainfall records. In general, the Indian sub-continent has a high positive OLR anomaly during the winter and pre-monsoon months and a moderate negative anomaly in the monsoon season. The distribution of OLR anomalies exhibits strong dependence on both temporal and spatial scales during the years with poor or excess monsoon rainfall.
\end{abstract}

\section{INTRODUCTION}

Over the Indian sub-continent, summer rainfall associated with the monsoon circulation has been found to have significant variability in terms of both space and time. Successful forecasts of the monsoon rainfall would therefore necessitate detailed knowledge of its spatial and temporal variability over the region. Summer rainfall in the tropics is usually associated with organised convective clouds, and these clouds modulate the Outgoing Longwave Radiation (OLR) observed from satellite sensors. Thus, to obtain dates of the monsoon onset and withdrawal from the time series of $5 \mathrm{~d}$ OLR means over the Indian subcontinent is a possibility with useful applications for remote northern regions in the Himalayas and also over the seas. Following this approach, several researchers have recently attempted to establish the dates of onset of the summer monsoon over the Indian sub-continent and adjoining seas (Arkin et al. 1987, 1989, Meisner \&

\footnotetext{
- On deputation from Bangladesh Space Research and Remote Sensing Organisation (SPARRSO), Dhaka, Bangladesh
}

Arkin 1987). Besides these, diagnoses of OLR data sets in relation to both short- and long-term variability and atmospheric teleconnections were conducted by Murakami (1980a, b), Heddinghaus \& Krueger (1981), Lau \& Chan (1983a, b), Prasad \& Verma (1985) and Gruber \& Chen (1988). Kilonsky \& Ramage (1976) discussed a technique for estimating tropical ocean rainfall from satellite observations. Richards \& Arkin (1981) established further relationships between satellitederived cloud cover and precipitation. Using INSAT-1B data, monthly mean OLR as well as Quantitative Precipitation Estimate (QPE) maps of India derived from OLR for the period June 1986 to December 1987 were published by the India Meteorological Department (IMD 1988). The QPEs derived from OLR were based on the general approach proposed by Richards \& Arkin (1981).

Elucidation of the nature of space-time variations in OLR over the Indian sub-continent in relation to summer monsoon activity is expected to yield insight into the behaviour of the monsoon rainfall. However, in a recent study, Haque \& Lal (1991) showed that distinct heterogeneities exist in different parts of the Indian subcontinent in terms of OLR and rainfall distributions. In view of this, an assessment of monsoon onset and with- 
drawal on a regional scale within the Indian sub-continent is considered more meaningful in order to examine the monsoon's progress/retreat with time. We have therefore, analysed 14 yr of NOAA OLR data to construct $5 \mathrm{~d}$ mean OLR indices and to obtain the onset and withdrawal dates of the summer monsoon for selected regions in the Indian sub-continent. The 7 regions ( $R 1$ to R7) identified for this study (Fig. 1) were chosen based on their unique climatological features in terms of the

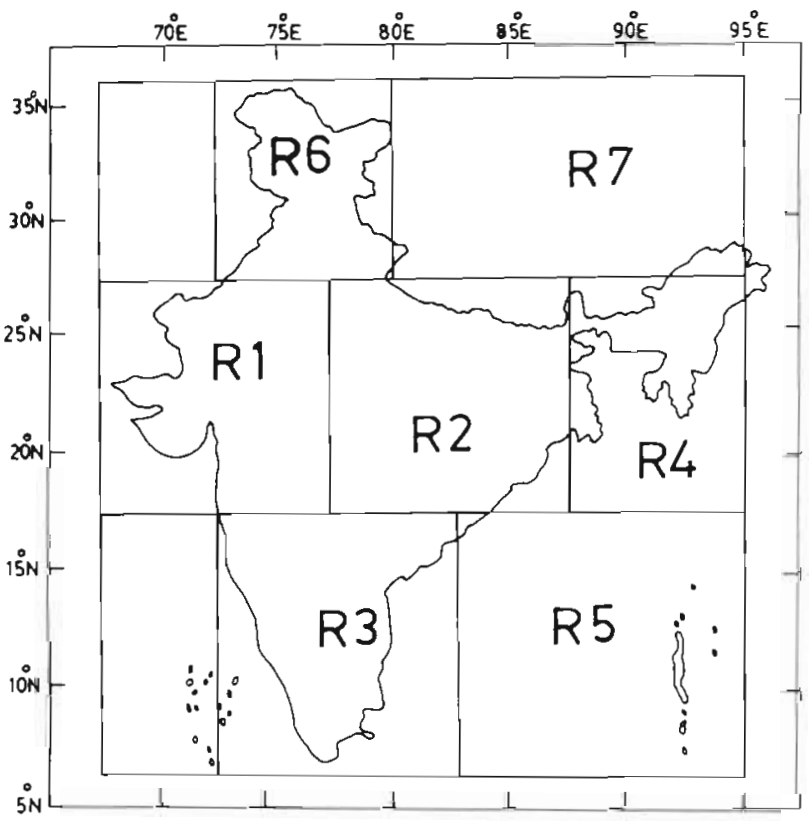

Fig. 1. Selected regions R1 to R7 over the Indian subcontinent

coefficients of variability of rainfall and surface temperature. For each region, the time series of $5 \mathrm{~d}$ mean OLR demonstrates its intraseasonal variability and allows for the determination of onset and withdrawal dates of the monsoon. The dates of onset and withdrawal for the 7 regions inferred from the OLR indices are compared with those reported by IMD based on rainfall observations.

With a view to examining the OLR distribution in years with poor, normal and excessive rainfall activity, and to understanding the intraseasonal as well as interannual variability of the OLR distribution over the regions, time series of monthly mean OLR and their standard deviations were derived. These values were used to compute OLR anomalies over each of the regions. The monthly standardized OLR anomalies were computed to obtain correlation matrices between the regions in years with varying monsoon rainfall activity over the Indian sub-continent. From these analyses, we infer the major characteristics of the spatial and temporal behaviour of Indian monsoon rainfall.

\section{DATA ANALYSIS}

The OLR data used in this study were the daily mean values of OLR over the Indian region $\left(7.5\right.$ to $37.5^{\circ} \mathrm{N}$ and 67.5 to $97.5^{\circ} \mathrm{E}$ ) at $2.5^{\circ}$ latitude and longitude intervals for 14 yr from June 1974 to May 1988. The Data and Information Service of the US National Oceanic and Atmospheric Administration (NOAA) compiled satellite-derived fields of OLR from June 1974 onwards. These data were obtained from the Climate Analysis Center, NMC, Washington, D.C., USA. The estimates of OLR were based on theoretical and empirical relationships between total infrared (IR) flux and the $11 \mu \mathrm{m}$ window radiance measurements by the scanning radiometer instruments on NOAA-2 to NOAA-5 satellites. In terms of temperature and for a nadir view, the regression equation relating OLR and IR radiance was assumed to take the form

$$
T_{\mathrm{f}}=T_{\mathrm{B}}\left(a+b T_{\mathrm{B}}\right)
$$

where $T_{\mathrm{f}}(\mathrm{K})=$ black body flux temperature; $T_{\mathrm{B}}(\mathrm{K})=$ narrow channel equivalent blackbody brightness temperature (EBBT); and $a$ and $b=$ constants (Ohring et al. 1984). OLR was then computed as $\delta T^{4}$, where $\delta$ is the Stefan-Boltzmann constant. Details of the derivation of the OLR fluxes are given in Gruber (1977). The NOAA-5 satellite was out of order from March to December 1978. Because of the lack of daily data for these 10 mo, $5 \mathrm{~d}$ means were not computed for 1978 . However, for monthly means, this 10 ma data gap was filled by the 6 yr monthly average ( 3 yr before and 3 yr after) OLR values for each month

The daily mean OLR data were used to derive $5 \mathrm{~d}$ means for each year on every grid point. For each grid point, there are 73 sets of pentads in a year (in leap years the 73rd set is a $6 \mathrm{~d}$ mean). The OLR indices for each region were computed by counting the number of grid points having values less than $240 \mathrm{~W}$ $\mathrm{m}^{-2}$ (long-term mean OLR for the Indian sub-continent) in the region and then dividing by the total number of grid points constituting the region. Indices using a threshold of $240 \mathrm{~W} \mathrm{~m}^{-2}$ appeared to define the large-scale annual cycle in monsoon area rainfall reasonably well (Arkin pers. comm.). We adapted a criterion to define the date of the monsoon onset in the following way, accepting the same threshold value. If more than $40 \%$ of a region had OLR values less than $240 \mathrm{~W} \mathrm{~m}^{-2}$ (OLR index 0.4 ) for a continuous $15 \mathrm{~d}$ period ( 3 consecutive pentads) between May 25 and June 15, the area was considered to be covered by convective clouds and under the thrust of active monsoon. From the 3 consecutive pentads having index values more than the threshold index 0.4 , the third day of the first pentad was taken as the date of onset of the summer monsoon in that region. Simi- 
larly, a criterion for the dates of the monsoon withdrawal from different regions was defined as follows. If more than $90 \%$ of a region had OLR values higher than $240 \mathrm{~W} \mathrm{~m}^{-2}$ (OLR index less than 0.1) and there was no revival of monsoon activity (OLR index did not exceed 0.4 for consecutive 3 pentads), the region was then considered to have become free from largescale convective clouds associated with monsoon circulation systems. The pentad among these low OLR indices which had the lowest index value was then considered as the date of monsoon withdrawal from that region.

Regions R6 and R7 have low temperatures almost throughout the year due to the high altitude of the snow-covered Himalayan range. Further, from November to March, frequent disturbances pass from west to east through these 2 regions and contribute substantially to the annual rainfall/snowfall over the region. As such, high OLR indices (greater than 0.4) prevail in these regions during most of the year. Therefore, we followed a different approach to identify the dates of onset and withdrawal of the summer monsoon for these 2 regions. Here we first looked for the pentad having the lowest OLR index since the beginning of the year. From there, the third day of the first pentad among 3 consecutive pentads having OLR index greater than 0.4 was considered as the date of the monsoon onset. Similarly, the date of monsoon withdrawal was the third day of the second pentad with the lowest index value in September-October of each year. In Region R3, the date of monsoon withdrawal was found to overlap the advent of the northeast monsoon in some years. An approach similar to that used for Regions R6 and R7 was therefore followed for this region to extract the date of monsoon withdrawal in the first/second week of October.

From the daily OLR values, monthly mean OLRs for each grid point were computed. The monthly mean OLR for specified regions was obtained by summing the monthly grid values in a region and then dividing the sum by the number of grid points comprising the region. The means of 12 mo gave the annual mean for each region. Subtracting the annual mean from each month's mean, we obtained the monthly OLR anomalies which were used to examine the intraseasonal as well as interannual variability of OLR distributions over the individual regions. Further, on dividing the monthly anomalies by the standard deviation, we obtained the standardized anomalies for each month of the year. The standardized OLR anomalies in the monsoon season in years with poor, normal and excess rainfall activity were used to compute the correlation statistics between the 7 regions following Murphy \& Katz (1985), to investigate the interrelationship between the regions in terms of OLR distributions.

\section{RESULTS AND DISCUSSION}

\section{Dates of summer monsoon onset and withdrawal derived from pentad OLR indices}

Using the time series of $5 \mathrm{~d}$ mean OLR indices, we determined objectively the summer monsoon onset and withdrawal dates for each of the 7 regions following the approach discussed above. The pentad numbers in which the dates of onset and withdrawal fall are listed in Tables 1 and 2 respectively for each of the 14 yr. Also listed in these tables are the pentad numbers in which the actual dates of the monsoon onset and withdrawal fall as per IMD records based on rainfall criterion. On average, the onset dates derived from the OLR indices are close to those derived on the basis of rainfall distributions (correlation coefficient, $\mathrm{r}=0.76$ ). It is also apparent that the onset occurred earliest in the Bay of Bengal region (R5) and progressed subsequently to the southern Indian peninsula (R3), West Bengal, Sikkim, Assam and adjoining states and Bangladesh (R4), east Madhya Pradesh, east Uttar Pradesh, Bihar, Orissa and adjoining Nepal (R2), the snowbound Himalayan region (R7), north Maharashtra, west Madhya Pradesh, Gujarat and Rajashtan (R1) and finally to the Punjab, Haryana, Himachal Pradesh and Jammu and Kashmir region (R6) in a regular fashion in each year (Table 1). It is possible that the monsoon onset occurs earliest in the Arabian Sea. However, as we have not included the Arabian Sea region in the present study, it is not possible to confirm this.

Correspondingly, monsoon withdrawal over the Indian sub-continent takes place in a progressive manner from north to south (Table 2). The earliest withdrawal of the monsoon rainfall in each of the 14 yr considered in this study is seen over the Jammu and Kashmir and the adjoining snowbound Himalayan regions (R6 and R7). Subsequently, the monsoon withdraws from northwest India (R1), central India (R2), northeast India including Bangladesh (R4), south Indian peninsula (R3), and finally disappears from the Bay of Bengal (R5). The pentads for the dates of monsoon withdrawal derived from the OLR indices coincide reasonably well with the dates of withdrawal reported by IMD based on rainfall distribution ( $\mathrm{r}$ $=0.75$ ) except in the south Indian peninsula (R3) where the OLR is often influenced by the arrival of the northeast monsoon in late October-early November. In Regions R6 and $R 7$, the cloudiness associated with western disturbances masks the otherwise high OLR values (low indices) expected with the withdrawal of the monsoon clouds in some years.

In 1977, the Indian sub-continent experienced normal monsoon activity with widespread rainfall over all the 7 regions considered in this study. Excessive rainfall was recorded during the monsoon season of 1983 in 
Table 1. Pentad number in which the date of monsoon onset falls for years 1974 to 1987 in each of the 7 selected regions R1 to R7 of the Indian sub-continent (based on OLR indices/rainfall records). $\mathrm{r}$ : linear correlation coefficient between OLR-derived pentads and pentads based on actual rainfall records. Significance levels $(\%)$ with sample size $(n)=13$ and degrees of freedom $(\mathrm{df})=11$ are also given

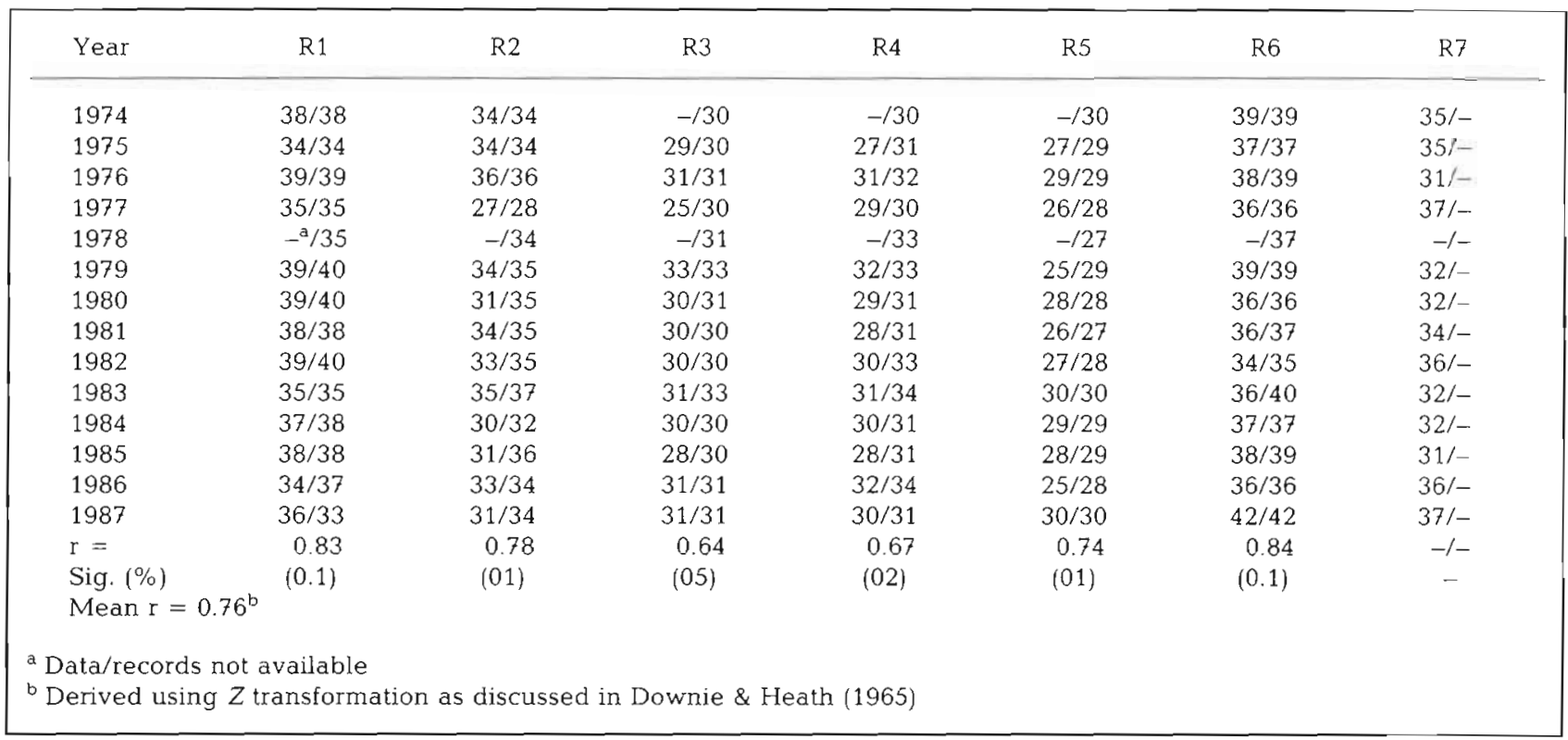

Table 2. Pentad number in which the date of monsoon withdrawal falls for years 1974 to 1987 in each of the 7 selected regions R1 to $R 7$ of the Indian sub-continent (based on OLR indices/rainfall records). r: linear correlation coefficient between OLR-derived pentads and pentads based on actual rainfall records. Significance levels (\%) with sample size $(\mathrm{n})=13, \mathrm{df}=11$ are also given

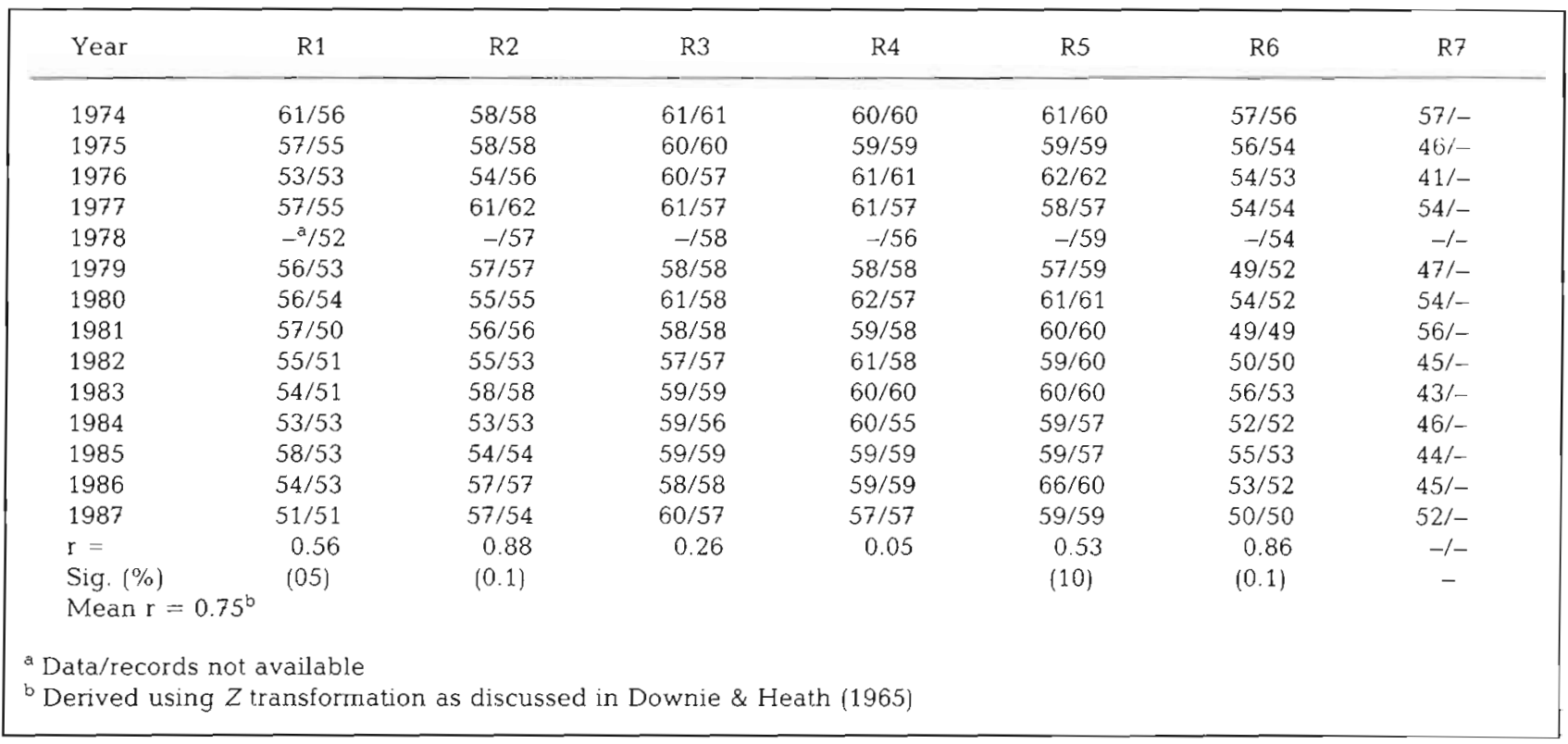

each region. In contrast, during 1987 the monsoon rainfall activity was below normal in all 7 regions. The time series of pentad OLR indices for each region during these 3 yr are depicted in Figs. 2 to 8 . From Fig. 2, it can be seen that in 1977 and 1983, the arrival of the monsoon in Region R1 was during 20 to 24 June (pentad 35), but the monsoon was delayed by 1 wk in 1987. The mean OLR indices for Region R1 during the monsoon season were $0.48,0.62$, and 0.37 in 1977, 1983 and 1987 respectively. This further illustrates that Region R1 had a higher number of overcast days in 1983 in spite of the fact that 2 breaks in the monsoon (each of 

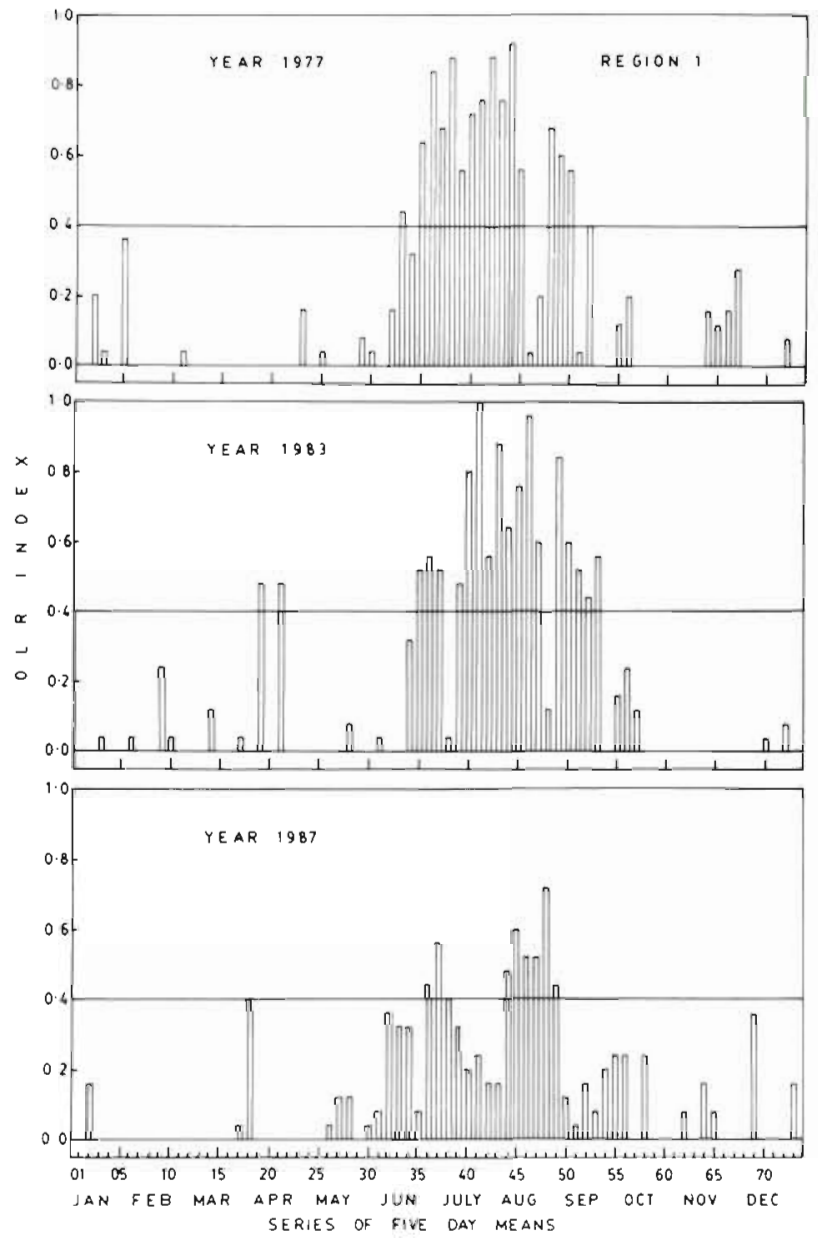

Fig. 2. Distribution of pentad OLR indices for Region R1 in selected years

3 to $7 \mathrm{~d}$ duration) occurred in that year. In 1987 the mean OLR index was considerably lower in Region R1 and monsoon activity (with partial overcast conditions and associated rainfall) was restricted to ca $30 \mathrm{~d}$ during August and early September.

In contrast to 1977, the duration of monsoon activity in Region R2 was higher in 1983, and was less in 1987 (Fig. 3). In the drought year of 1987, the advance of the summer monsoon in Region R2 was delayed by a month. Further, the withdrawal of the monsoon from Uttar Pradesh and Madhya Pradesh (Region R2) was about 2 wk earlier than its normal date. The mean OLR indices for Region R2 during the monsoon seasons of 1977, 1983 and 1987 were $0.55,0.80$ and 0.69 respectively. The mean OLR indices for Region R3 during the monsoon season were $0.65,0.77$, and 0.75 in 1977,1983 and 1987, respectively. Also, the span of the monsoon season with the number of cloudy days and associated rainfall activity was longer in 1983, but shorter in 1987 in comparison to 1977 (Fig. 4). As evident from OLR index distributions, 3 monsoon breaks and an early
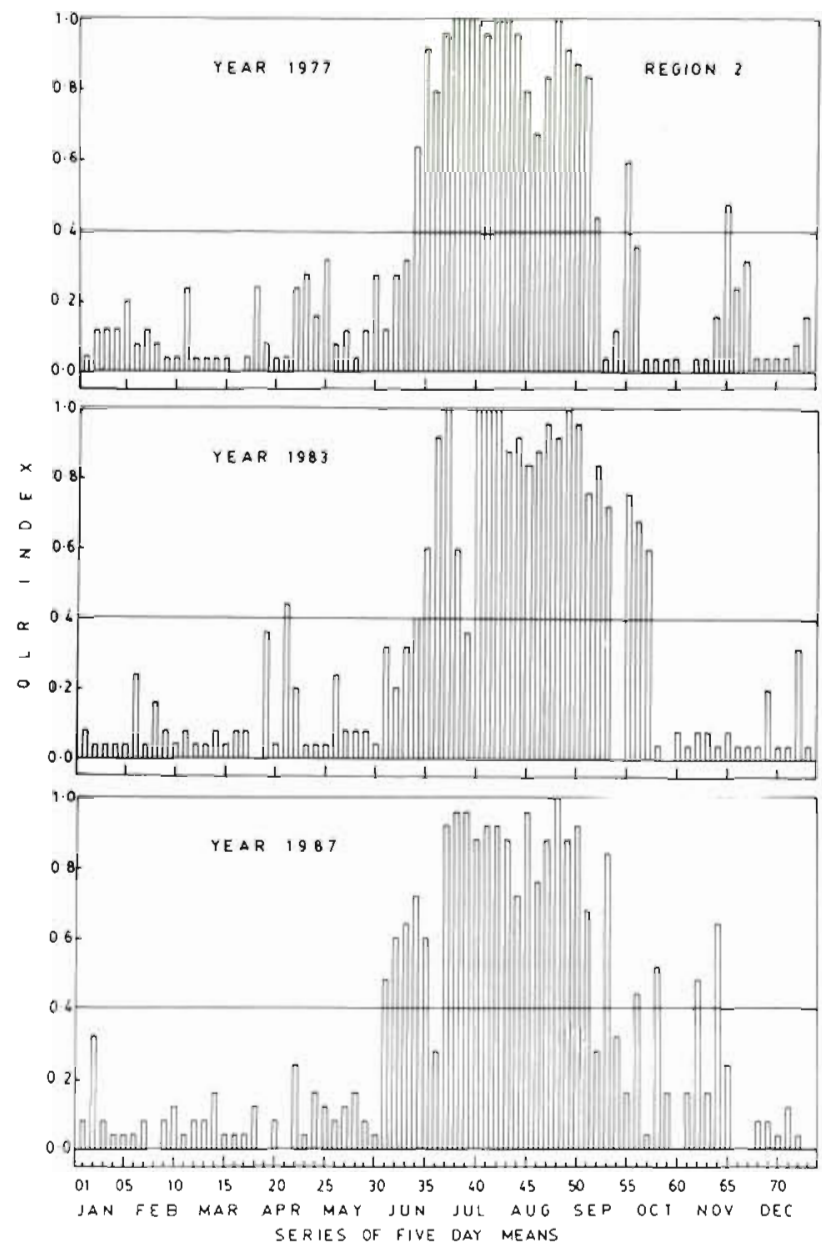

Fig. 3. Same as in Fig. 2 but for Region R2

withdrawal of the monsoon contributed to deficient rainfall in 1987 in Region R4 (Fig. 5). The mean OLR indices for Region R5 during the monsoon season were $0.67,0.86$, and 0.77 in 1977, 1983 and 1987, respectively. Prolonged breaks in the monsoon, as well as an early withdrawal, led to deficient rainfall in 1987 in Region R5 (Fig. 6). Note that the mean OLR indices for each of the 7 regions were computed taking into account the number of active monsoon days in the individual years and not the total number of days in the monsoon season. In view of this, even though the year 1987 was reported as a drought year, the OLR indices for this year are higher than the indices for the year 1977.

Figs. $7 \& 8$ show typical distributions of the OLR indices throughout the year for the snowbound Himalayan region which includes Jammu and Kashmir and the adjoining states (Regions R6 and R7). The OLR indices are higher than 0.4 in most of the 73 pentads of the year in Regions R6 and R7. This is explained by the fact that these regions have fre- 


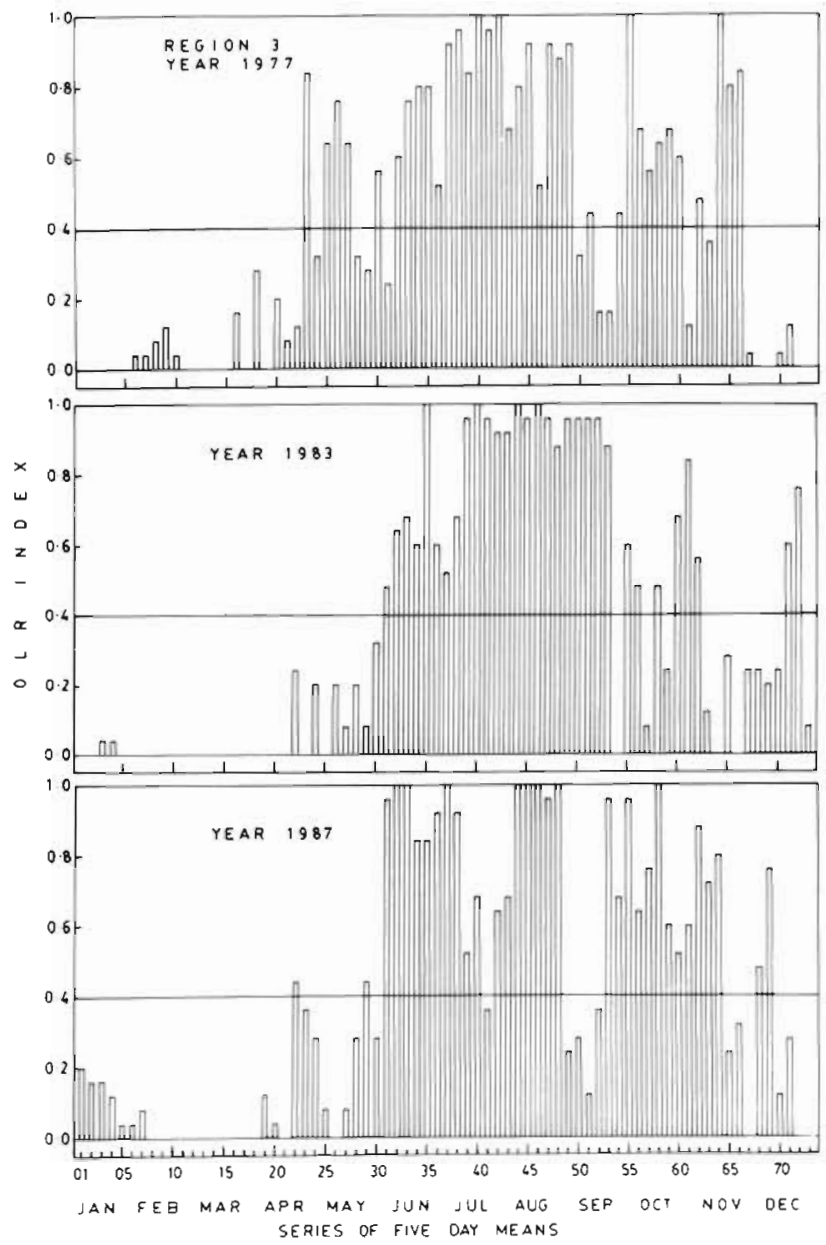

Fig. 4. Same as in Fig. 2 but for Region R3

quent cloudy days throughout the year associated with both monsoon activity (during summer) and the passages of western disturbances (during winter). The significantly high OLR indices in Region R7 could also be attributed to lower than average OLR due to high altitude of the region and extremely high albedo (reflectivity) in the presence of perennial snow cover. The mean OLR indices for Region R6 during the monsoon season were $0.50,0.51$, and 0.37 in 1977, 1983 and 1987, respectively. The infrequent cloudiness associated with the lower OLR indices in 1987 contributed to the deficient rainfall in Region R6 during this monsoon season.

In view of the findings discussed above, it appears possible that the OLR indices could be used as a tool to identify monsoon onset and withdrawal dates, as well as to define large-scale monsoon rainfall variability over the selected regions. This inference, of course, does not imply a predictive application of the methodology but merely indicates a technique for monitoring the behaviour of the Indian summer monsoon progressively over the Indian sub-continent.
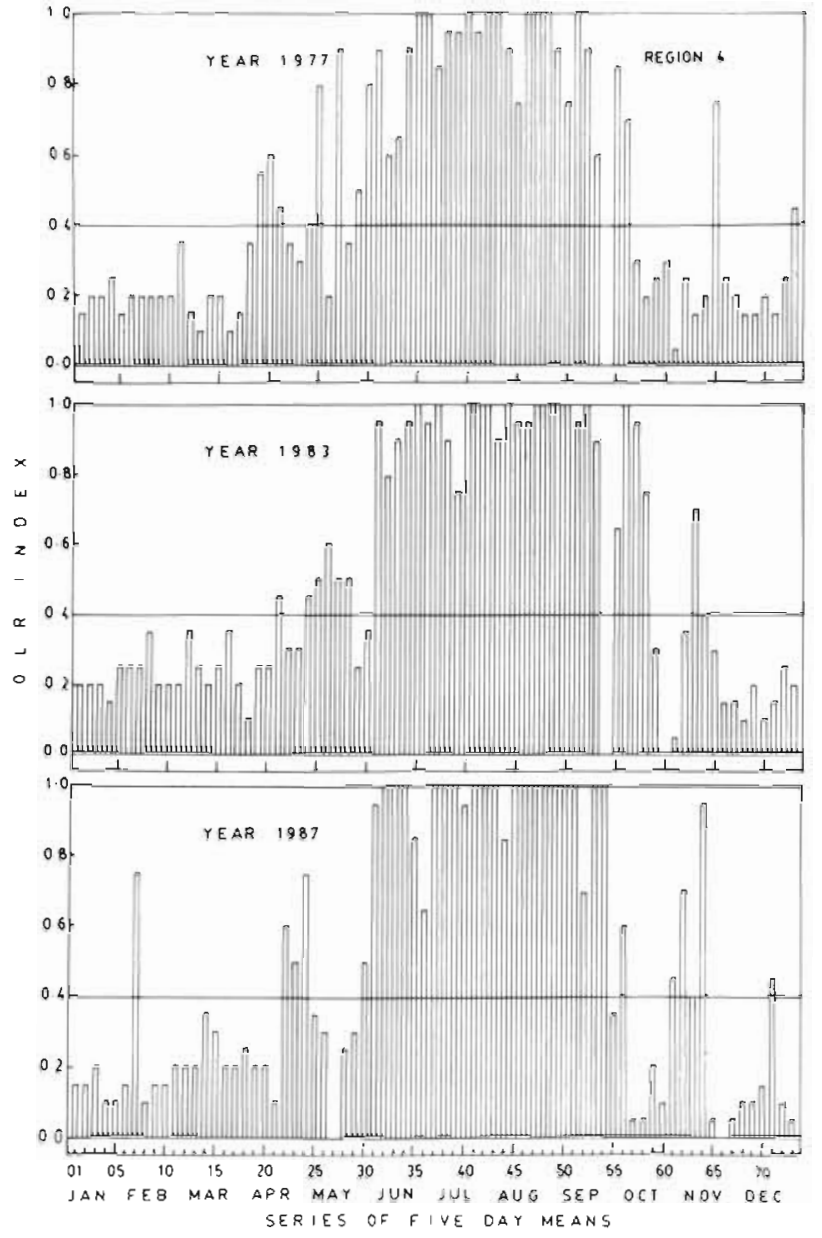

Fig. 5. Same as in Fig. 2 but for Region R4

Intra- and interannual variability of OLR anomalies over selected regions

The monthly OLR anomalies for Regions R1 to R7 during 1975, 1982 and 1985 are depicted in Figs. $9 \& 10$. In 1985, a fair distribution of the summer monsoon rainfall occurred over all the 7 regions of the Indian subcontinent and adjoining sea. The most severe drought of the decade over the Indian sub-continent, with deficient rainfall in 33 out of 35 subdivisions of India and Nepal, was recorded in 1982. Based on rainfall records, the country experienced an active monsoon with excessive summer rainfall in 1975 in most of the meteorological sub-divisions. From Fig. 9, it is apparent that the high. positive (>10 $\mathrm{W} \mathrm{m}^{-2}$ ) OLR anomalies during the winter in Regions R2, R6 and R7 declined to a moderate to high negative anomaly $\left(-2\right.$ to $\left.-10 \mathrm{~W} \mathrm{~m}^{-2}\right)$ during the monsoon season. This decline is supported by frequent cloudy conditions in the observed data records which contributed positively to a normal monsoon rainfall activity in 1985 in these regions. Region R1 had low rainfall activity in 1985 . This is supported by the OLR 

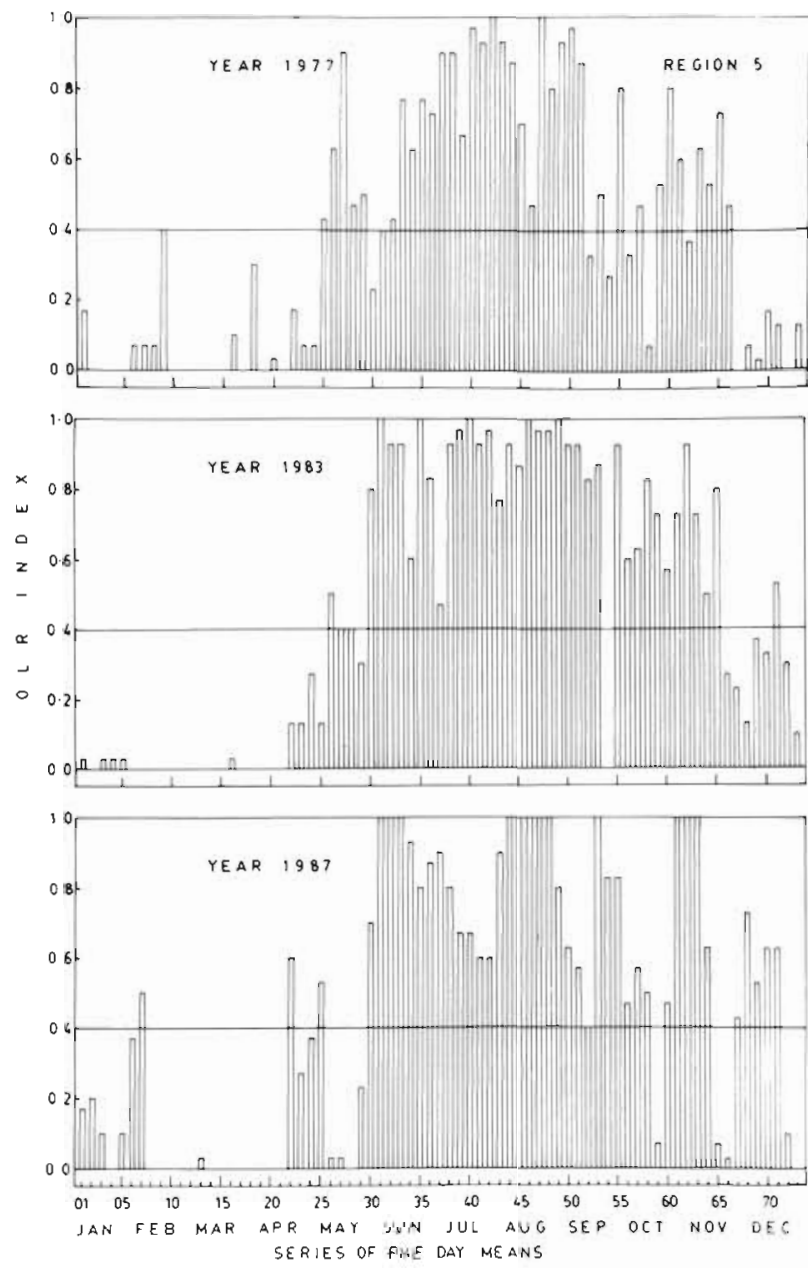

Fig. 6. Same as in Fig. 2 but for Region R5

anomaly in this region during the monsoon months (rainfall recorded in Region R1 was only $340 \mathrm{~mm}$ in 1985 as compared to the mean seasonal rainfall of $534 \mathrm{~mm}$ ). The year 1975 had high negative OLR anomalies ( -2 to $-20 \mathrm{~W} \mathrm{~m}^{-2}$ ) in Regions R1, R2, R6 and R7, which supported the excess rainfall activity under the influence of the southwest monsoon. Interestingly the OLR anomalies in all these regions during the winter season of 1982 were highly negative $\left(-8\right.$ to $\left.-16 \mathrm{~W} \mathrm{~m}^{-2}\right)$, but as the southwest monsoon approached the OLR anomalies became positive, indicating clear sky conditions. Obviously not much convective activity could take place in these regions in the monsoon season of 1982, which led to severe drought conditions.

The monthly OLR anomalies of 1975, 1982 and 1985 for Regions R3, R4 and R5 are illustrated in Fig. 10. Negative OLR anomalies (zero to $-6 \mathrm{~W} \mathrm{~m}^{-2}$ ) in the premonsoon months (February to May) of 1975 were attributed to substantial amount of annual rainfall in Region R3 as against 1982 and 1985 (rainfall for the premonsoon months of 1975,1982 and 1985 were recorded
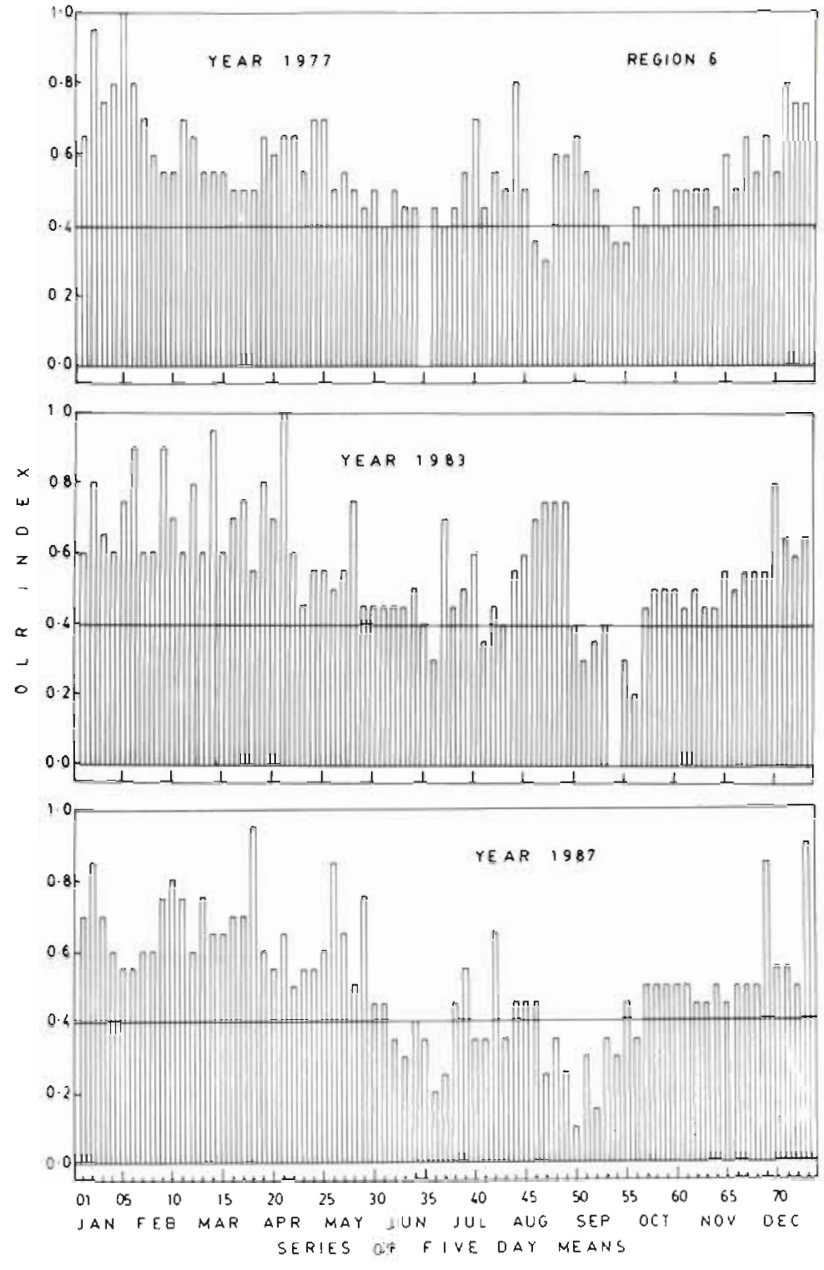

Fig. 7 Same as in Fig. 2 but for Region R.6

as 106,89 and $89 \mathrm{~mm}$ respectively). During the monsoon months, near-zero to negative OLR anomalies ( 3 to $-10 \mathrm{~W} \mathrm{~m}^{-2}$ ) were observed in 1975 indicating good rainfall activity (seasonal rainfall was reported as $961 \mathrm{~mm}$ ) in Region R3. In contrast, near-zero to moderate positive OLR anomalies ( -2 to $10 \mathrm{~W} \mathrm{~m}^{-2}$ ) in 1982 suggested predominantly clear sky conditions and less precipitation during the monsoon season (seasonal rainfall was reported as $668 \mathrm{~mm}$ ). In 1985, only marginal negative OLR anomalies ( 2 to $-5 \mathrm{~W} \mathrm{~m}^{-2}$ ) were observed (the seasonal rainfall reported was $660 \mathrm{~mm}$ ) in the monsoon season. Significant differences were observed in the distribution of OLR anomalies during the postmonsoon season (October to January) in the 3 yr considered here. In this season, 1982 had highly positive OLR anomalies with a peak at $12 \mathrm{~W} \mathrm{~m}^{-2}$ while $1975 \mathrm{had}$ highly negative anomalies with a peak at $-15 \mathrm{~W} \mathrm{~m}^{-2}$. Rainfall reported for the post-monsoon seasons of 1975 , 1982 and 1985 was 351, 245 and $304 \mathrm{~mm}$ respectively.

It is interesting to note that, while most of India had severe drought in the monsoon season of 1982, Bangla- 


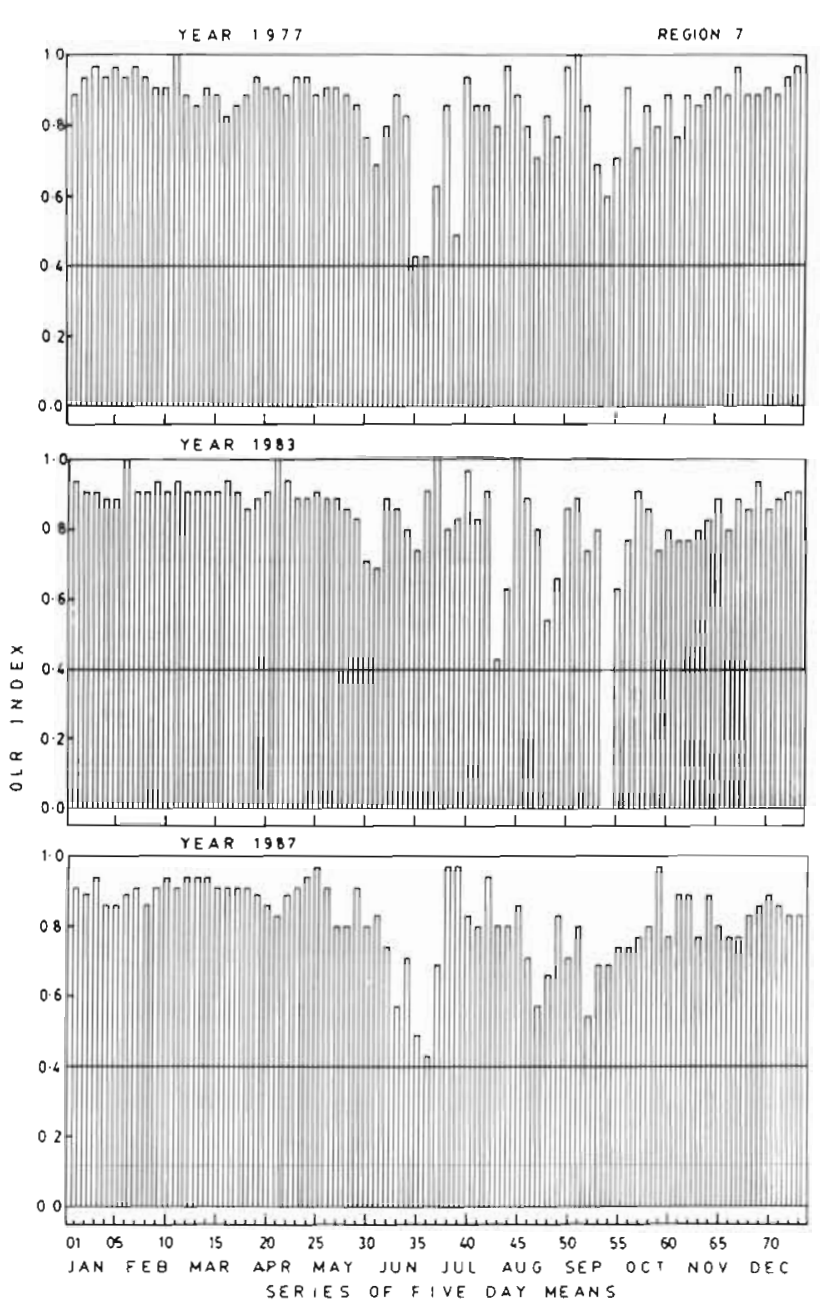

Fig. 8. Same as in Fig. 2 but for Region R7

desh (Region $\mathrm{R} 4$ ) had reasonably good monsoon rainfall activity, according to rainfall records. This could be attributed to a stronger Bay of Bengal branch of the southwest monsoon in relation to the Arabian Sea branch, as well as the regional orography (Khasi and Jayantia hills of Meghalaya and Assam). While the majority of meteorological subdivisions in India had excess rainfall during the monsoon months of 1975 , Bangladesh and adjoining regions had deficient rainfall activity. This is also confirmed from the distribution of OLR anomalies of Region R4 (Fig. 10). Similar conditions also prevailed over the Andaman and Nicobar islands, as confirmed from the OLR distribution of Region R5. In both Regions R4 and R5 during the northeast monsoon season (October-November), positive OLR anomalies in the range of 5 to $12 \mathrm{~W} \mathrm{~m}^{-2}$ were observed which were attributed to poor rainfall activity in 1982 as against 1975 and 1985 when moderate to high negative OLR anomalies $\left(-5\right.$ to $\left.-15 \mathrm{~W} \mathrm{~m}^{-2}\right)$ were seen.

The foregoing discussion indicates that, in years with normal monsoon activity, the Indian sub-continent
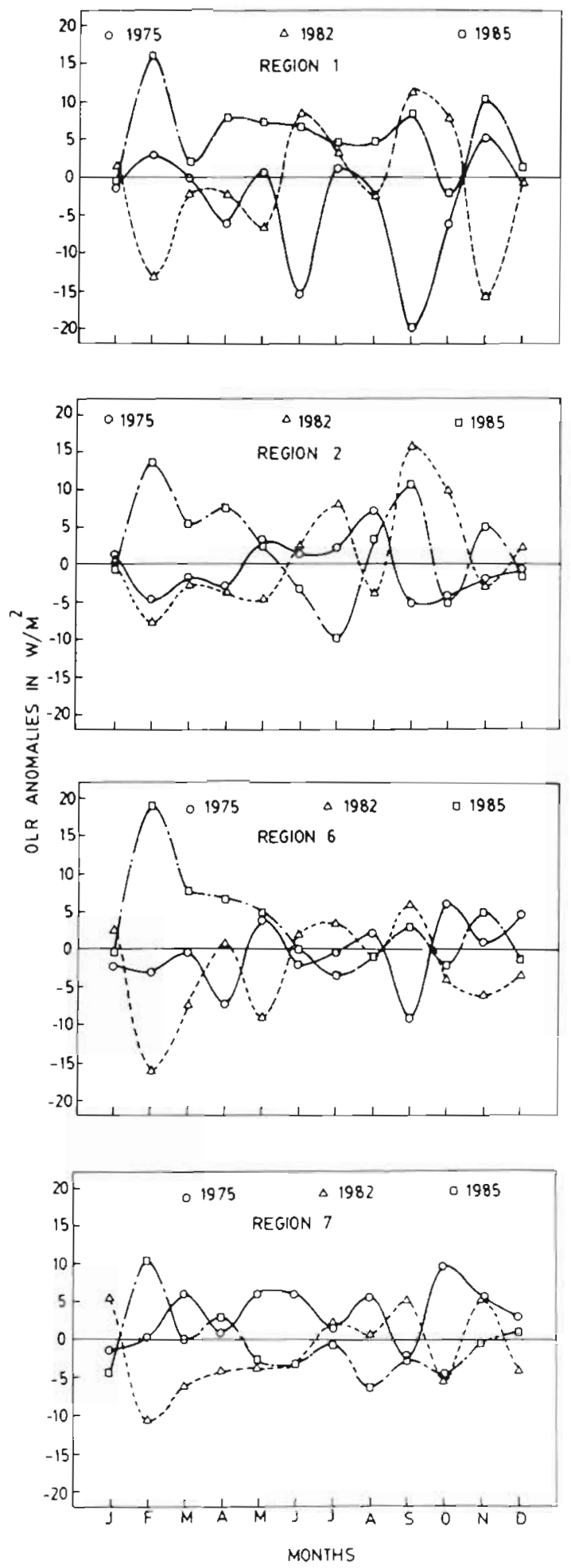

Fig. 9. Monthly distribution of OLR anomalies $\left(\mathrm{W} \mathrm{m}^{-2}\right)$ for Regions R1, R2, R6 and R7 in selected years

generally has a high positive OLR anomaly during the winter and pre-monsoon seasons with a moderate negative anomaly in monsoon months. This distribu- 

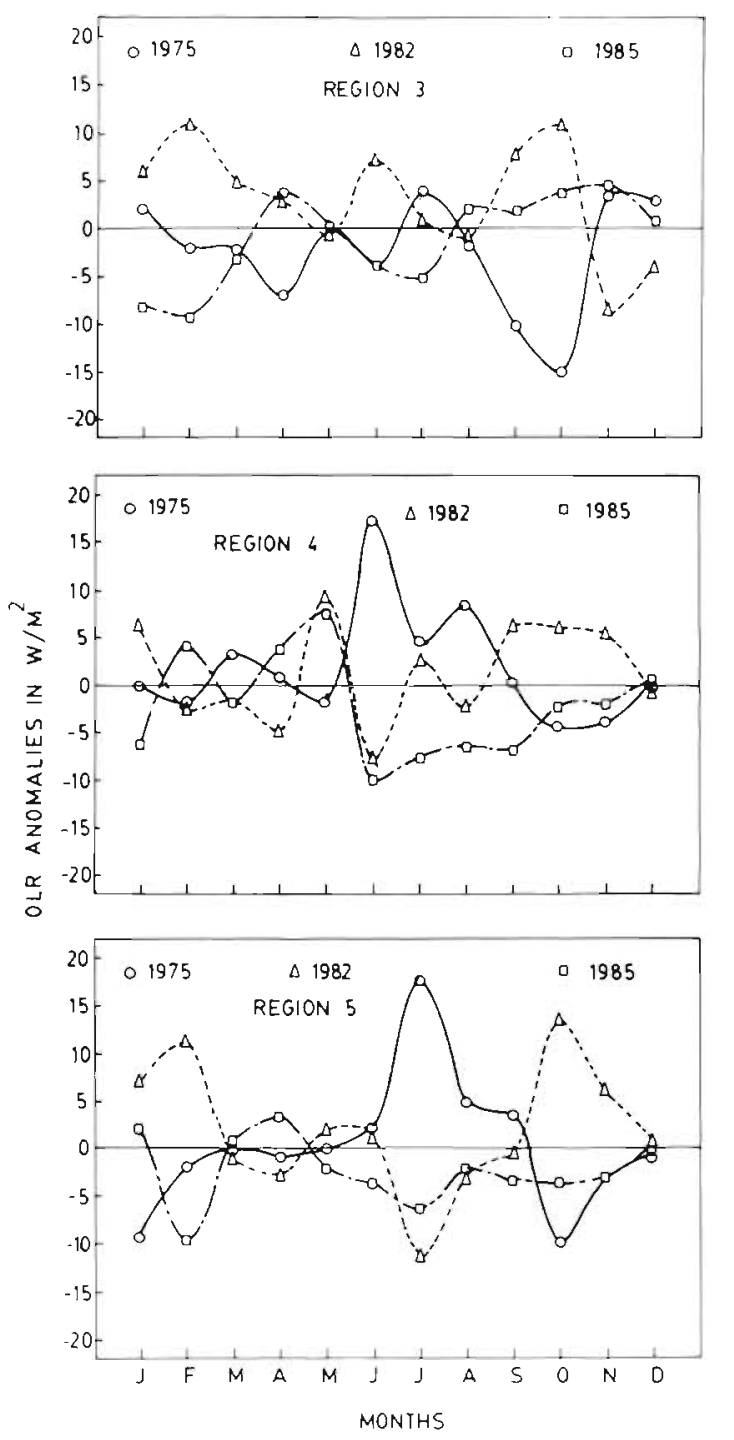

Fig. 10. Same as Fig. 9 but for Regions R3, R4 and R5

tion of OLR anomalies is highly disturbed and becomes regionally dependent during both years with excess and those with deficient rainfall activity.

\section{Spatial variability of standardized OLR anomalies over selected regions}

In an earlier paper, Haque \& Lal (1991) investigated the statistical coherency between the selected regions over the Indian sub-continent from OLR and rainfall distribution patterns. Linear and multiple correlations were derived to examine the nature of existing heterogeneities between the selected regions both from long-term annual and seasonal (based on 14 yr of data) OLR as well as rainfall anomalies. To supplement on this aspect, we have now examined the relationship between the 7 regions based on yearwise OLR distributions. Since the summer monsoon is the principal contributor to annual rainfall in the majority of the 7 regions considered here, we have primarily confined our investigation to the OLR anomalies of the monsoon season. The linear correlations among the regions were derived for each of the $14 \mathrm{yr}$ for which OLR data were available with a view to investigating temporal as well as spatial variability of OLR over the Indian sub-continent. The correlation matrices of Regions R1 to R7 for the selected years 1975, 1982 and 1985 representing excess, poor and normal rainfall distributions respectively are listed in Table 3.

Table 3. Linear correlation matrices of monthly monsoon OLR anomalies for the selected regions during the years 1975, 1982 and 1985. In parentheses level of significance $(\%)$

\begin{tabular}{|c|c|c|c|c|c|c|c|}
\hline & R1 & $\mathrm{R} 2$ & R3 & R4 & R5 & R6 & R7 \\
\hline \multicolumn{8}{|c|}{1975 (Excess monsoon rainiall) } \\
\hline R1 & 1.00 & $\begin{array}{l}0.94 \\
(10)\end{array}$ & -0.81 & $\begin{array}{l}0.89 \\
(10)\end{array}$ & -0.67 & $\begin{array}{l}0.92 \\
(10)\end{array}$ & 0.21 \\
\hline R2 & & 1.00 & -0.75 & $\begin{array}{l}0.99 \\
(01)\end{array}$ & -0.79 & 0.82 & 0.31 \\
\hline R3 & & & 1.00 & -0.79 & $\begin{array}{l}0.87 \\
(10)\end{array}$ & $\begin{array}{r}-0.97 \\
(05)\end{array}$ & -0.70 \\
\hline R4 & & & & 1.00 & $\begin{array}{r}-0.88 \\
(10)\end{array}$ & 0.81 & 0.46 \\
\hline R5 & & & & & 1.00 & -0.77 & -0.83 \\
\hline R6 & & & & & & 1.00 & 0.49 \\
\hline R7 & & & & & & & 1.00 \\
\hline \multicolumn{8}{|c|}{1982 (Drought conditions) } \\
\hline R1 & 1.00 & $\begin{array}{l}0.93 \\
(10)\end{array}$ & 0.61 & 0.38 & -0.01 & $\begin{array}{l}0.96 \\
105)\end{array}$ & -0.26 \\
\hline R2 & & 1.00 & 0.76 & 0.66 & 0.30 & $\begin{array}{l}0.95 \\
05\end{array}$ & -0.04 \\
\hline R3 & & & 1.00 & $\begin{array}{l}0.92 \\
(10)\end{array}$ & 0.76 & 0.54 & 0.60 \\
\hline R4 & & & & 1.00 & 0.51 & 0.41 & 0.69 \\
\hline R5 & & & & & 1.00 & 0.00 & $\begin{array}{l}0.90 \\
(10)\end{array}$ \\
\hline R6 & & & & & & 1.00 & -0.34 \\
\hline $\mathrm{R} 7$ & & & & & & & 1.00 \\
\hline \multicolumn{8}{|c|}{1985 (Normal rainfall) } \\
\hline R1 & 1.00 & $\begin{array}{l}0.99 \\
(01)\end{array}$ & 0.23 & 0.60 & -0.43 & $\begin{array}{l}0.97 \\
(05)\end{array}$ & 0.21 \\
\hline R2 & & 1.00 & 0.08 & 0.46 & -0.57 & $\begin{array}{l}0.96 \\
(05)\end{array}$ & 0.34 \\
\hline R3 & & & 1.00 & 0.85 & 0.65 & 0.12 & $\begin{array}{r}-0.89 \\
(10)\end{array}$ \\
\hline R4 & & & & 1.00 & 0.46 & 0.57 & -0.52 \\
\hline R5 & & & & & 1.00 & -0.40 & -0.75 \\
\hline R6 & & & & & & 1.00 & 0.34 \\
\hline R7 & & & & & & & 1.00 \\
\hline
\end{tabular}


In years with normal monsoon rainfall activity, as well as drought years, Regions R3 and R4 are positively correlated (correlation coefficient, $r=0.85$ and 0.92 ). However, in years with excess summer rainfall activity, Region R3 has a significant negative correlation ( $\mathrm{r}=$ -0.79 ) with Region R4 in terms of OLR distribution. A similar trend between $R 4$ and $R 5$ is seen during years with excess summer monsoon rainfall ( $\mathrm{r}=-0.88$ ). Region $\mathrm{R} 7$ has a strong negative correlation ( $\mathrm{r}$ is between -0.70 and -0.89 ) with both Regions R3 and R5 during excess and normal monsoon activity years. This apparently suggests that, during years with normal or above average rainfall activity, while Regions R3 and $\mathrm{R} 5$ receive good precipitation, there is a likelihood of less rainfall/snowfall over the Himalayan belt. In drought years, however, R7 has a positive correlation with Region R3 ( $r=0.60)$ and significantly so with Region R5 ( $r=0.90)$. This confirms the general observation that during a drought year relatively more precipitation occurs over both the southern peninsula and the Bay of Bengal and Himalayan regions.

From the linear correlation analyses of OLR anomalies for Regions R1 to R7 in selected years, we may thus conclude that R1, R2 and R6 are interrelated in terms of OLR anomalies irrespective of the strength of the monsoon activity. However, under drought conditions, while north and northwest India (Regions R1 and R6) have deficient rainfall, the Bay of Bengal, Assam and east Himalayan regions (R4, R5 and R7) may receive significant rainfall/snowfall.

\section{CONCLUSIONS}

The principal conclusions drawn from this study include: (1) OLR indices using the threshold of $240 \mathrm{~W}$ $\mathrm{m}^{-2}$ could be used as a tool to identify the monsoon onset and withdrawal dates of each of the selected regions over the Indian sub-continent. (2) The monsoon onset appears to progress from southeast to northwest over the Indian sub-continent with the exception of the southernmost tip of the south Indian peninsula. (3) The monthly OLR anomalies demonstrate intra- as well as interannual variability in monsoon rainfall (in each of the selected regions) reasonably well. (4) The seasonal distribution of OLR anomaly is regionally dependent during years with both excess as well as deficient monsoon rainfall. (5) As seen from the linear correlation matrices of the OLR anomalies for the 7 regions in selected years, if drought conditions prevail over north and northwest India, both Assam and the adjoining Bay of Bengal and eastern Himalayan region should receive substantial rainfall during the summer monsoon months.

In the tropics, convection could well be regarded as an immediate agent in the origin of regional anomalies. Accordingly, continuous monitoring of OLR anomalies from satellites over the global tropics offers an exciting potential for understanding large-scale rainfall variability. Considering that a large compilation of OLR data from NOAA, ERBS, NIMBUS and TIROS-N (AVHRR) satellites are now available, regional studies for monitoring interannual variability in cloudiness and precipitation in relation to OLR should be useful in order to arrive at a predictive methodology in the realm of the monsoon circulation.

Acknowledgement. The authors are grateful to Dr Phillip A Arkin of the Climate Analysis Center, NMC, Washington, D.C., USA, for providing us the OLR data used in this study and his useful comments and advice during the coarse of study. The authors express their sincere thanks to reviewers for their useful suggestions to improve the clarity of the paper.

\section{LITERATURE CITED}

Arkin, P. A., Marsico, D.C., Kelkar, R. R., Krishna Rao, A. V. R (1987). Indian monsoon rainfall 1986-1987, Proc. 12th Climate Diagnostics Workshop, Salt Lake City

Arkin, P. A., Krishna Rao, A. V R., Kelkar, R. R. (1989). Largescale precipitation and Outgoing Longwave Radiation from INSAT-1B during the 1986 south-west monsoon season, J. Climate 2: 619-628

Downie, N. M.. Heath, R. W. (1965). Basic statistical methods. Harper and Row, New York, p. 158-159

Gruber, A. (1977). Determination of earth-atmosphere radiation budget from NOAA Satellite data. NOAA Technical Rep. NESS76, NOAA, U. S. Dept. of Commerce, Washington, D.C., $28 \mathrm{pp}$.

Gruber, A., Chen, T. S. (1988). Diurnal variation of Outgoing Longwave Radiation, J. Climatol. 8: 1-16

Haque, M. A., Lal, M. (1991). Diagnosis of satellite-derived Outgoing Longwave Radiation in relation to rainfall in India. J. Meteor. and Atmos. Phys.: 1-13

Heddinghaus, T R. Krueger, A. F. (1981). Annual and interannual variations in Outgoing Longwave Radiation over the tropics. Mon. Wea. Rev. 109: 1208-1218

India Meteorological Department (1988). Satellite-derived monthly mean precipitation and Outgoing Longwave Radiation maps over India and neighbourhood for the period June to December, 1987. IMD publication, New Delhi, $46 \mathrm{pp}$.

Kilonsky, B. J., Ramage, C. S. (1976). A technique for estimàtIng tropical ocean rainfall from satellite observations. J. appl. Meteorol. 15: 972-975

Lau, K.-M., Chan, P. H. (1983a). Short-term variability and atmospheric teleconnection from satellite observed Outgoing Longwave Radiation. Part I: Simultaneous relationships. J. Atmos. Sci. 40: 2735-2750

Lau, K.-M., Chan, P. H. (1983b). Short-term variability and atmospheric teleconnection from satellite observed Outgoing Longwave Radiation. Part II: Lagged correlations. J. Atmos. Sci. 40: 2751-2767

Meisner, B. N., Arkin, P. A. (1987). Spatial and annual variation in the diurnal cycle of large-scale tropical convective cloudiness and precipitation. Mon. Wea. Rev. 115 $2010-2032$

Murakamı, T (1980a). Temporal variations of satellite 
observed OLR over the winter monsoon region. Part I. Long Period (15-30 day) oscillations. Mon. Wea. Rev. 108: $408-426$

Murakami, T. (1980b). Temporal variations of satellite observed OLR over the winter monsoon region. Part II: Short-period (4--6 day) oscillations. Mon. Wea. Rev. 108: $427-444$

Murphy, A. H., Katz, R. W (1985). Probability, statistics, and decision making in the atmospheric sciences. Westview Press, Boulder, p. 101-152

Editor: T Oikawa
Ohring, G., Gruber, A., Ellingson, R, G. (1984). Satellite determination of the relationship between total longwave radiation flux and infrared window radiance. J. Climate appl. Meteorol. 23: 416-425

Prasad, K. D., Verma, R. K. (1985). Large-scale features of satellite-derived OLR in relation to monsoon circulation over the Indian region. J. Climatol. 5: 297-306

Richards, F. Arkin, P. A. \{1981). On the relationship between satellite-observed cloud and precipitation. Mon. Wea. Rev. 109: 1081-1093

Manuscript first received: March 20, 1990

Revised version accepted: January 18, 1991 